\title{
A New Framework for Selecting Composite Indicators to Assess Sustainability of a Destination
}

\author{
By Elham Falatooni* \\ Willem Selen ${ }^{\dagger}$ \\ Don $\mathrm{Kerr}^{\text {t }}$
}

\begin{abstract}
The indicators currently used for assessing the sustainability of tourist destinations are either too complex or too site-specific for managers to benefit from them. There is definitely a need for a balanced approach in the development of indicators that are easy to understand and cover both contextual specificity and global issues. The aim of this paper is to develop such a framework, extending from site-specific attributes to a global scale. It is argued that common challenges in the construction of composite indicators, being related to their narrow focus, complexity and inefficient weighting, could be addressed by a comprehensive literature search to extract indicators that are holistic in nature. It is suggested that a systematic review of the literature aiming to identify potential holistic indicators around four types of destination should be the basis of this new framework. Destination-specific criteria will be used for extracting relevant indicators while frequency of use in leading publications will serve as a filter. Finally, the outcome of this process is expected to be a composite indicator which balances destination specificity and global sustainability issues.
\end{abstract}

Keywords: Sustainability Assessment, Composite Indicators, Systematic Literature Review, Tourism Destination

\section{Introduction}

Sustainable tourism development is defined as tourism that "... makes optimal use of environmental resources; respects the socio-cultural authenticity of host communities; ensures viable, long-term economic operations, providing socio-economic benefits to all stakeholders; requires the informed participation of all relevant stakeholders, as well as strong political leadership; and so maintains a high level of tourist satisfaction" (UNWTO 2004: 7). Tourist destinations generally present specific or unique leisure experiences, including the natural environment, cultural heritage or artistic sites that are very fragile and need to be protected. The impact of tourism on the environment has been a global concern for some time and sustainable tourism development began to attract the attention of both researchers and decision-makers after the World Commission on Environment and Development report (World Commission on

\footnotetext{
* PhD Candidate, School of Business - FABL, University of the Sunshine Coast, Australia.

${ }^{\dagger}$ Professor, School of Business - FABL, University of the Sunshine Coast, Australia.

*Associate Professor, School of Business - FABL, University of the Sunshine Coast, Australia.
} 
Environment and Development 1987). Nowadays, a tourism destination can be viewed as a business ecosystem (Schianetz and Kavanagh 2008) defined as a complex business environment including numerous small and large interacting organizations and stakeholders (customers, market intermediaries, lead producers, competitors and suppliers) with individual business activities, but depending on each other for their success (Moore 1993, Peltoniemi 2006). Recently, a shift in focus from development of sustainability to measurement of sustainability is observable, with studies focusing on developing tools to measure and monitor various aspects of sustainability in different sectors of tourism destinations (Choi and Sirakaya 2006). This has resulted in development of either general indicators which were found to be too complex for use by policymakers or consensual indicators, resulting from stakeholder engagement, which are subject to respondent bias and manipulation (Tanguay et al. 2013). Moreover, sustainability assessment of tourism destinations must address the growing complexity of operating in a business ecosystem and embrace scientific analysis methods and technical solutions. Manning (1999) postulated the development of alternative indicators that focus on operational aspects, a concept that has caught on recently with demand for operationally focused tourism indicators increasing substantially in recent years (Tanguay et al. 2013).

Yet, the challenge is to develop indicators that are both well grounded, simple and reliable enough to guide the development of sustainable tourism destinations (Torres-Delgado and Palomeque 2014), as their use has been hampered by technical and conceptual difficulties (Torres-Delgado and Saarinen 2014). In particular, previous studies of indicator systems have shown more "failures than successes, either because the proposed indicators did not meet what was required or because they were not based on relevant information or data" (Tanguay et al. 2013: 863). For example, sustainability assessment through simple traditional indicators that include a huge number of individual elements is too difficult and cumbersome for decision-makers and stakeholders to handle. Moreover, while each indicator may represent a separate sustainability dimension, cumulative sustainability effects may not impact in a similar way or at the same time. Development of a successful indicator system calls for a combination of a scientific approach (objective indicators) and policy-maker approach (subjective indicators). In this regard, Composite Indicators are suggested as a multidimensional assessment tool, with the ability to summarise information to facilitate "decision-making" and ensure stakeholder involvement. A limited number of studies have developed such composite indicators (Blancas et al. 2011, Lozano-Oyola et al. 2012, Singh et al. 2012, Perez et al. 2013, Torres-Delgado and Saarinen 2014), yet display issues of appropriate weighting, accuracy or ignoring the importance of particular crucial issues in sustainability assessment (Mikulić et al. 2015). Recently, a review of the use of indicators to assess sustainable tourism development (Torres-Delgado and Saarinen 2014) furthermore indicated a need for a balanced approach in the development of indicators that are easy to understand and cover both contextual specificity and global issues, such as climate change impacts of tourist mobility. 
While a substantial number of studies have developed different sets of indicators, including subjective, objective and composite indicators, until now no comprehensive and systematic review has been applied to extract holistic overarching composite indicators to assess sustainability holistically at destinations. This paper aims to develop a set of holistic and overarching composite indicators through a comprehensive literature review that covers socio-cultural, environmental and economic dimensions of sustainability within a tourism destination. In addition, the purpose of such a comprehensive literature review is to provide an alternative for the weighting of indicators by using the frequency of each indicator as it has appeared in leading literature. Moreover, gaps associated with incomplete sets of indicators for measuring sustainable tourism destinations are closed through a systematic literature search to review all relevant existing indicators (Mikulić et al. 2015). Another purpose is to develop indicators that are easy to understand and balance both contextual specificity and "core indicators" that reflect the goals of sustainable development at a more holistic or global scale (Roberts and Tribe 2008, Torres-Delgado and Saarinen 2014). This will be accomplished through extraction of relevant indicators from the comprehensive literature review, using destination specific-criteria.

\section{Sustainability Assessment of a Tourism Destination}

Tourism destinations rely on natural, cultural, physical and human resources that result in capabilities that are non-substitutable, rare and unique (Cracolici and Nijkamp 2009), in order to attain their goals, develop competitive advantages, bring economic benefits and provide better value for their host population, tourists and firms (stakeholders) (Barney 1991, Grant 2010). Tourism destinations are not only characterised by different products, services and stakeholders; but also by different cultures and values that impact on the destination's host population (Jamal and Jamrozy 2006). In this context, tourism consumes resources and impacts on environmental, social and cultural attributes of the local destination (Cater and Cater 2007, Myers et al. 2011). Such impacts may be both positive and negative (Choi and Sirakaya 2006, Myers et al. 2011, Calgaro et al. 2014). Economic benefits and preservation of cultural heritages are examples of positive impacts that, through preservations of cultural and historic sites, monuments and traditional buildings, as well as protected areas and natural parks may attract more tourists to these destinations. Yet, tourism destinations are also threatened by "excessive tourism exploitation" (Candela and Figini 2012: 566) that may result in natural and environmental degradation, negative social and cultural impacts and habitat fragmentation (Choi and Sirakaya 2006, Twining-Ward 2007). Other negative impacts relate to infrastructure damage, strained transportation systems, vandalism, crime, drugs, degradation of a destination's local customs and language, conflict and fear of foreigners (Choi and Sirakaya 2006, Myers et al. 2011). Finally, tourism activities in a destination may reduce quality of life of the host population (Haralambopoulos and Pizam 
1996, Mowforth and Munt 2008). Such undesirable side-effects have led to a growing concern for the conservation and preservation of natural resources and cultural heritages, human well-being and the long-term economic viability of communities, leading to the concept of a "sustainable tourism destination" (Lee 2001, Miller et al. 2010, Wickens et al. 2015). Sustainable tourism requires involvement of local residents and stakeholders in planning and improving sustainability in tourism destinations as a business ecosystem (Candela and Figini 2012). In order to achieve sustainable development at a destination level, all existing practices and potential impacts need to be monitored, as well as corrective measures and necessary assessments are determined. Developing sustainability at a tourism destination requires efficient management and hence appropriate assessment and monitoring to improve the host residents' quality of life, while protecting the natural environment. In addition, it should provide a high-quality travel experience for tourists and economic returns for the host communities (Larson and Herr 2008, Perez et al. 2013). In this regard, a progressive balance is paramount between tourist satisfaction (need for economic growth) and natural resource consumption (environmental protection) (Franzoni 2015). To assess and monitor sustainability development, different types of assessment tools have been proposed, with "indicators" having received considerable attention.

Definitions of sustainability have proliferated, from fifty definitions in 1989 to five thousand definitions today (Heinberg 2010). Bleischwitz and Hennicke (2004) state that any concrete definition of sustainability undoubtedly depends on societal discursive processes and as such may change as a result of socio-cultural value changes. Two theoretical lenses underpin the concept of sustainability: the institutional view and the resource-based view. The institutional view states that change is frequently motivated and caused by businesses looking for social approval (Meyer and Rowan 1977). The resource-based view lens, on the other hand, underlines internal firm performance as a result of accumulating valuable resources and capabilities that lead to superior firm performance (Barney 1991). With the environmentally resource-based view, resources are identified as either renewable or non-renewable, with the sustainable use of both to be considered with high political and scientific priority (World Commission on Environment and Development 1987).To develop sustainability, all three pillars of sustainability, including social, ecological and economic factors, defined as "people, planet and prosperity", should be considered (La Viña et al. 2003). The fundamentals of sustainability and sustainable development are in essence the same to "meet the needs of the present generation without compromising the ability of future generations meet their own needs" (Marien 1992). Three fundamental principles of sustainable development can be identified. The first principle is based on people needs (Moldan et al. 2012). The Millennium Ecosystem Assessment specified the essential aspects of human well-being as supporting basic requirements for health, freedom, good life and social relationship (Board 2005). The second principle of sustainable development insists on a healthy and productive human life which is in harmony with nature (Moldan et al. 2012).The term "harmony with nature" emphasizes the environmental dimension of human life which is depended on 
numerous relationships and interdependencies as part of a complex natural and social web. The third principle of sustainable development highlights the dynamic and long-term nature as an essential feature of sustainability that simultaneously captures present and future generations alike (Moldan et al. 2012).

Recently, the focus on sustainability has shifted from sustainability development to sustainability assessment. Sustainability assessment has been considered an essential "tool" for converting the intention of sustainable development into practical development (Pope et al. 2004). Devuyst (2001: 9) defined sustainability assessment as a "tool that can help decision-makers and policy-makers decide what actions they should take and should not take in an attempt to make society more sustainable". Sustainability assessment integrates strategic environmental assessment (SEA) and environmental impact assessment (EIA) methods. Most of the sustainability assessment ideas driven from EIA and SEA make valuable and understandable contributions toward sustainability and they can extend their boundaries to cover additional sustainability concerns (Sheate 2001, Pope et al. 2004). Two common, but different, methodologies can be used for assessing sustainability. These are The Monetary Aggregation Method, popular among economists and Physical Indicators, mostly used by scientists and researchers (Singh et al. 2012). The economic approach looks at sustainability as a part of economic development and includes resource accounting, defining conditions of sustainability as weak or strong and the modelling of sustainability growth (Singh et al. 2012). Yet, such economic models are criticised for not being able to comprehensively measure sustainability due to serious functional restrictions in discipline-specific analytical capacity (Spangenberg 2005). The most common assessment tools for sustainable tourism destination are (Singh et al. 2012):

- Environmental Impact Assessment (EIA): While promising as sustainability based assessment that is flexible and integrative, sustainability is a much wider concept. Furthermore, this assessment takes place in the later stage of decision-making procedures and has limited success in the evaluation of alternatives (Singh et al. 2012).

- Ecological Management System (EMS): It is an administrative tool for environmental assessment, based on elementary sustainability principles. This tool does not work properly when more elaborate planning activities and objectives are not incorporated in the EMS.

- Life Cycle Assessment (LCA): It is a product or service based assessment and covers the whole spectrum from resources selection to disposal process. Such assessment process becomes cumbersome when the object of assessment is multidimensional.

- Ecological Footprint (EF): It is based on efficiency improvements and sustaining national living standard (land and water). This assessment relies on appropriate normalization and weighting.

- Adaptive Environmental Assessment (AEA): It is a systematic process based on outcomes of operational programs. The theoretical 
complex structure of the AEA is too difficult to understand especially by non-expert users (Blancas et al. 2010a).

- Sustainability Indicators (SI): These are defined as "the set of measures that provide the necessary information to better understand the links and the impact of tourism on the cultural and natural setting in which this takes place and on which it is strongly dependent" (Manning 1996).

Because of the multidimensional nature of sustainability (environmental, socio-cultural and economic), indicators are seen as an effective means to capture a complex process, while representing the real condition of the whole system (Alkemade et al. 2014). The European Community Models of Sustainable Tourism (ECMST) project was one of the first researches in sustainability in tourism to use indicators. Early studies of indicators emphasised on upgrading tourists' accommodations, host residents' prosperity and sustaining economic benefits and cultural identity (Torres-Delgado and Saarinen 2014). According to James (2001) indicators contribute to monitoring and assessing sustainability at destinations in three ways: first by categorizing the "key factors of change", subsequently by determining the "evolution" of these key factors and finally by identifying their potential threats. When identifying sustainable indicators, three tourism destination factors need to be taken into consideration (Schianetz et al. 2007: 21):

- "Destinations are often located in or close to ecologically fragile and/or culturally sensitive areas;

- Destinations are characterised by highly dynamic processes and tourism development is inherently unstable and often unpredictable;

- Destinations constitute a conglomerate of many small independent but interacting businesses which are also directly and/or indirectly dependent on each other".

Furthermore, indicators should (European Environmental Agency 1999, Valentin and Spangenberg 2000, White et al. 2009, Torres-Delgado and Palomeque 2014a):

- Be simple to understand and directionally clear.

- Be easy to communicate among various stakeholders regarding the processes involved.

- Promote information exchange.

- Have high accuracy and transparency.

- Be useable by laypersons, not only by experts.

In order to assess sustainability at tourism destinations, the level of destination (unit of analysis) should be clearly defined. Indicators can be used at different levels: national, regional, specific (i.e. coastal zones), key tourist sites at destinations (i.e. historic sites, beaches), tourism companies (i.e. hotels, tour operators) and individual tourism establishments (i.e. marinas) (UNWTO 2004). 
Next, sustainability assessment criteria need to be established, which can be determined bottom-up or top-down (Pope et al. 2004). Finally, the unit of measurement should be determined, which can be either quantitative (percentage, raw data and ratios) or qualitative (normative and nominal indicators, category indices and opinion-based indicators). Indicator development has been governed by their "mission of assessment" (European Environmental Agency 1999), "utility to decision makers" (UNWTO 2004) or scientific (objective) and policy-maker (subjective) approaches (Shields et al. 2002, Rametsteiner et al. 2011, Tanguay et al. 2013). Furthermore, (Torres-Delgado and Saarinen 2014) recently distinguished between simple indicators which involve simple data treatment or provide information directly from field and complex indicators providing multidimensional measurement and resulting from a combination of various simple indicators. They argued that simple indicators should be used for partial solutions or for detecting specific impacts, while complex indicators provide an integrated and broad overview. The choice of what indicators to use is dependent on working scale, quality of available information and assessment requirements. A holistic indicator system generally covers both qualitative and quantitative aspects and as such a combination of objective and subjective indicators. The argument is made that objective indicators are necessary for accurate assessment and underlining expenditures, while subjective indicators are also to be included to gather the level of satisfaction by internal and external clients (tourists and residents) (Perez et al. 2013). Moreover, indicators at a destination level should clarify the link between industry and sustainable tourism and monitor its impact on the cultural and natural environment. Each aspect of sustainability must be evaluated by each component of the system, individually or in combination with the rest of the system (Blancas et al. 2010b). In order to assess such a complex system, as well as simplify complex measurement, a multidimensional assessment tool is required, which is encapsulated by composite indicators. Composite Indicators exhibit the ability of summarizing information to facilitate "decisionmaking", with stakeholder involvement (Blancas et al. 2011, Lozano-Oyola et al. 2012, Singh et al. 2012, Perez et al. 2013, Torres-Delgado and Saarinen 2014). While such composite indicators have great potential, some pitfalls are discussed next, as well as how this paper resolves the issues rose through a comprehensive literature review approach with appropriate filtering.

\section{Pitfalls of Traditional Composite Indicator Development}

Composite indicators are widely used to summarize information and boost decision making processes by involving stakeholders' perceptions. As such, composite indicators contribute to public-policy decisions and present relevant information to stakeholders. Composite indicators are a mathematical combination of individual indicators with no common unit of measurement or obvious weighting scheme (Singh et al. 2012, Perez et al. 2013). Each individual indicator represents a particular dimension of sustainability (Saisana and Tarantola 2002). Composite indicators simplify complex measurement; and are therefore the most 
preferred assessment tool to measure multidimensional concepts, such as sustainability (Saisana and Tarantola 2002, Perez et al. 2013) and sustainable tourism (Lozano-Oyola et al. 2012: 661). Composite indicators system provide reliable results if based on proper evidence. Likewise, the quality of the composite would below when non-expert users are unsure about relevant certifications or testing of the composites (Singh et al. 2012). Saltelli (2007) and Torres-Delgado and Palomeque (2014) define the main goals of composite indicators as to provide a holistic overview of the system, to summarize complex issues, to reduce the number of listed indicators and to attract public interest.

Different mathematical methods have been proposed to build composite indicators, with the particular method governed by the concept being assessed, the user's skill level and the intended application of the composite indicators (LozanoOyola et al. 2012). The process of developing a composite indicator involves the following steps (Nardo et al. 2005):

- Which sub-indicators are to be selected?

- How are selected indicators divided into different classes?

- Is normalization required or not?

- Which weighting method is to be used?

- How is information aggregated?

Recently, Torres-Delgado and Saarinen (2014) revisited the steps involved in developing composite indicators. First, issues that needs to be measured need to be clearly understood and defined, including availability of required information and a conceptual framework. Next, a set of appropriate simple indicators is to be selected, which are subsequently standardised using weighting and aggregation methods. In this regard, the OECD has outlined a 10 step procedure for constructing composite indicators (Commission 2008), as illustrated in Table 1.

Table 1. Key Steps to Construct Composite Indicators

\begin{tabular}{|l|l|}
\hline 1. Theoretical framework & 2. Data selection \\
\hline 3. Imputation of missing data & 4. Multivariate analysis \\
\hline 5. Normalization & 6. Weighting and aggregation \\
\hline 7. Uncertainty and sensitivity analysis & 8. Back to data \\
\hline 9. Link to other indicators & 10. Visualization of the results \\
\hline
\end{tabular}

Source: The Organisation for Economic Co-operation and Development (Commission 2008). Prepared by Authors.

Varying methodologies have been used to build composite indicators to assess sustainability in tourism destinations. Delphi surveys were adopted by Miller (2001) and Choi and Sirakaya (2006) to propose sustainability indicators for tourism destinations, with Miller's use of indicators focused on encouraging tourists to select their holiday destinations, while Choi and Sirakaya (2006) focus on community development within a sustainability framework (Bossel 1999) proposed indicators that are based on expert opinions of different social, political 
and scientific backgrounds. The above methods may lack from inclusion of particular perceptions that impact significantly on local stakeholders. McCool et al. (2001) highlighted the importance of stakeholders' perceptions by including various hospitality sector opinions from restaurants and resorts when building sustainability indicators. McElroy and De Albuquerque (1998) developed a tourism penetration index to illustrate the serious threat of mass tourism to the sustainability of small Caribbean islands. The composite indicators that were derived assessed environmental, economic and social effects of the tourism industry, but resulted in only three indicators which is not deemed holistic enough. More recently, Perez et al. (2013) presented a methodology to build 39 composite indicators to assess sustainability of "nature-based" destinations. While this study focused on dimensions of social and economic sustainability, it failed to include environmental and cultural impacts. Torres-Delgado and Palomeque (2014) provide a set of simple objective indicators to assess the multidimensional and complex concept of sustainability. While their proposed indicators are deemed scientifically valid, their practical adoption has failed, because of a lack of engagement of local stakeholders (Blancas et al. 2010a, Blancas et al. 2011), and Lozano-Oyola et al. (2012) developed similar composite indicators for three types of destinations (coastal, cultural and rural), pointing to the need to customise indicators by destination to maximise efficiency. This point was re-iterated by Ahmad et al. (2013) who state that each destination is recognized as a unique business ecosystem, including different types and number of organizations, services, products, natural resources, attractiveness, stakeholders and a different range of interrelated impacts on the host population that all add to the complexity and call for its own set of sustainability indicators. Furthermore, studies to date that address the development of composite indicators face the recurring challenge of "indicator weighting", which impacts significantly on the assessment and analyses (Mikulić et al. 2015) and which may vary a lot based on the weighting procedure used. More specifically, weighting of indicators is important in constructing composite indicators, as individual indicators may not be of equal importance. Hence, weighting has a significant impact on the effectiveness of a composite indicator system. Yet, previous studies have failed to provide a clear explanation for the underlying reasons for their selected weighting methods, which could be subjective (based on Delphi and expert panel surveys) or data-centric (using factor analysis, goal programming or principal component analysis) (Mikulić et al. 2015). Other studies of sustainable tourism indicators (TwiningWard and Butler 2002, Castellani and Sala 2010) excluded the weighting stage and only applied equal weights, did not report on weightings in the result (Jurado et al. 2012, Perez et al. 2013) or failed to aggregate individual indicators (LozanoOyola et al. 2012). Another problem associated with weighting is the lack of performance-level considerations at the individual destination-level. For example, methods like FA (Factor Analysis) or PCA (Principal Component Analysis) apply indicator performance-levels at multiple destinations, yielding varying indicator levels across different destinations, raising the question: "whether the low weight for some indicators is truly reflecting the fact that this indicator is a relatively less important issue in all of the analysed destinations?" (Mikulić et al. 2015: 313). 
Furthermore, if the assumption of strong correlations among sustainability indicators is not valid, using a FA or PCA-based weighting method to construct composite indicator would be unreliable or even illogical. Hence, application of such weighting methods under such circumstances may result in indicators which are not sufficiently reliable to measure sustainability at the tourism destination.

Finally, as stated by Lozano-Oyola et al. (2012: 660): "A large number of studies use indicators to determine the level of sustainable tourism at target destinations. However, these studies remain primarily theoretical, due to the incomplete quantification of indicators".

The above mentioned pitfalls of incomplete quantification, weighting, lack of stakeholder inclusion, non-holistic sustainability assessment and lack of easyto-understand practical implementation are addressed in a novel approach for developing holistic, composite indicators using a comprehensive literature review approach of all currently available indicators. Such an approach, with its filtering and weighting based on frequency of appearance in the literature, is discussed next.

\section{Novel Composite Indicator Selection through a Systematic Literature Review}

The use of composite indicators is considered an effective approach to measure sustainability development by simplifying problems, summarising complexity, attracting public interest, providing a general overview and focusing attention (Saltelli 2007). Yet, current methodologies for development of such indicators suffer from "uncertainty" and "weighting" problems, caused by incorrect data collection and imputation, as well as erroneous data standardization, normalization, aggregation and weighting (Singh et al. 2012, Mikulić et al. 2015). In addition, as highlighted earlier, some indicator development still exhibited a lack of stakeholder inclusion, non-holistic sustainability assessment and a technical difficulty that is hard to grasp for practical implementation by non-expert stakeholders. This paper addresses a number of the above mentioned pitfalls through the use of a novel comprehensive literature review approach for selecting appropriate composite indicators to assess sustainability of a tourism destination.

A large number of studies have focused on the development of various indicators, yet such studies may not have covered all relevant dimensions of sustainability in a tourism destination individually or collectively (Blancas et al. 2011, Cottrell et al. 2013, Cucculelli and Goffi 2015, Franzoni 2015). A comprehensive literature review of composite indicator development for measuring sustainability of a tourism destination will provide different sets of data and a mix of quantitative/qualitative methods, with a combination of validated results, that will better inform the user across the wider scope of tourism and sustainability in terms of environmental impacts, land and energy use, residents' and tourists' well-being and the like.

A comprehensive literature review in our context is a multi-step procedure to compile a universal list of past and present studies on sustainability indicators of tourism destinations and consists of two main stages: a systematic literature search and extraction of composite indicators. 


\section{Stage 1}

The systematic literature search will identify studies that involved the construction/development of all forms (composite, objective and subjective) of sustainability indicators in tourism. This stage involves a comprehensive search of different electronic databases and online libraries, which include mainstream published journals, as well as other literature, such as monograph literature that is not controlled by commercial publishers (Evans et al. 2011).

For selection of composite indicators, the systematic literature search will start with key words drawn from different combinations of sustainability, tourism, composite indicators, objective indicators, subjective indicators, destination, resident well-being, tourist well-being, sustainable effects, quality of life, stakeholders, local communities, tourist satisfaction and resident satisfaction. Subsequent database searches will start with "sustainable tourism" and "tourism destination" as subject areas of the search. After initial screening and removal of publications not deemed relevant for the selection of sustainability indicators within our context of tourism destinations, potential papers will be retained according to their title and abstract, to be read in full. Papers and publications to be included from this list for later indicator selection will be filtered based on the following principles:

- Study is related to measuring/developing sustainability at tourism destinations.

- Study developed a set of sustainability indicators in a tourism context that are subjective, objective or composite; or sustainability indices in tourism.

- Study used a weighting procedure to construct indicators.

- Study was based on holistic principals of sustainability (economic, environmental and/or socio/cultural).

- Study focused on sustainability criteria published by The Western Australian State Sustainability Strategy (Pope et al. 2004):

a) Long-term economic health.

b) Equity and human welfare and rights.

c) Biodiversity and ecological integrity.

d) Quality of life and settlement efficiency.

e) Heritage, sense of place, regions and communities.

f) Develop net benefit.

g) Common good resources.

h) Precaution and non-invasive native scrub (non-INS) risk reduction.

i) Promote hope, vision and interactive change.

The above systematic literature eventually produces a list of relevant publications from which indicator selection is made for the selection of relevant composite indicators to measure sustainability holistically for the selected tourism destination. 
Next, a large number of composite indicators, along with their baselines and attributes for implementation, will be selected and subsequently reduced by a systematic process of grouping of over lapping indicators. In particular, duplicate indicators; irrelevant, non-sustainable indicators; and indicators under a different name but same outcome measurement, will be removed from the primary list of indicators. Next, sustainability indicators in their main list need to be categorized as socio-cultural, environmental or economic indicators, as follows:

- Socio-cultural indicators monitor the level of society welfare (Rosenström and Mickwitz 2004). For social indicators, setting targets is quite difficult due to the intractability and multiplicity of the origins of the problems (Moldan et al. 2012). In terms of sustainability, socio-cultural indicators need to reflect the perspective of future generations. In our tourism destination context, Blancas et al. (2011) state that socio-cultural sustainability indicators should include the public services available to the tourist, the tourist's sense of security and the preservation of the destination's cultural heritage. Other features include the development of a tourist destination to ensure that population levels are maintained with a balanced infrastructure and good distribution facilities and ensuring the well-being of the destination's population is looked after. Furthermore, socio-cultural indicators assess the impact of tourism on cultural concepts, such as changes to values, norms and beliefs (Carrera and Mack 2010).

- Indicators will be categorized as Economic sustainability indicators when they represent direct and indirect economic benefits of tourism, visitor satisfaction and the long-term viability of tourism demand (Blancas et al. 2011). Such indicators can also include the quality and quantity of tourist services, such as accommodation and restaurants, as well as the level of competitiveness of the destination, represented by the attractiveness of the destination products. They can also represent the impact of seasonal tourist activity, employment and the destination's transport and infrastructure.

- Indicators will be categorized as Environmental sustainability indicators (Blancas et al. 2011) when they assess energy consumption, water utilisation, waste and wastewater treatment, pollutant emission, noise level, visual pollution and how well the destination's natural resources as well as historical sites are protected ( $\mathrm{Hu}$ and Wall 2005, Hackett and Moore 2011).

The systematic literature review will be used to extract relevant indicators based on Australian strategies and priorities. In view of Australia being a signatory to the Kyoto protocols to lessen greenhouse gas emissions, it must meet its sustainability obligations and hence the tourism industry is prompted to minimize the impact of their products or services on the social and natural environment of tourism destinations. This is encapsulated in the sustainability criteria published by the Western Australian State Sustainability Strategy (WASSS 2003), which apply to Australia as a whole. This completes Stage 1 of the systematic literature review. 
Stage 2

Subsequently, the resulting indicators from Stage 1 will then be weighted based on the frequency of appearance of each indicator in leading literature, to reflect the relative importance of that indicator in the literature, after first taking into account the relevance of available indicators as filtered in Stage 1 across the three dimensions of sustainability for the tourism destination under consideration. The importance weighting of the resulting indicators in the literature is derived as follows:

$$
\mathrm{IW}_{\mathrm{i}}=\frac{\mathrm{F}_{\mathrm{i}}}{\mathrm{NP}}
$$

where,

IW $_{\mathrm{i}}$ : Importance weight of Indicator,

NP: Number of papers relevant to the destination as identified in Stage 1,

$\mathbf{F}_{\mathrm{i}}$ : Frequency of appearance of i-th Indicator within NP.

Figure 1. Framework for Selecting Relevant Composite Indicators

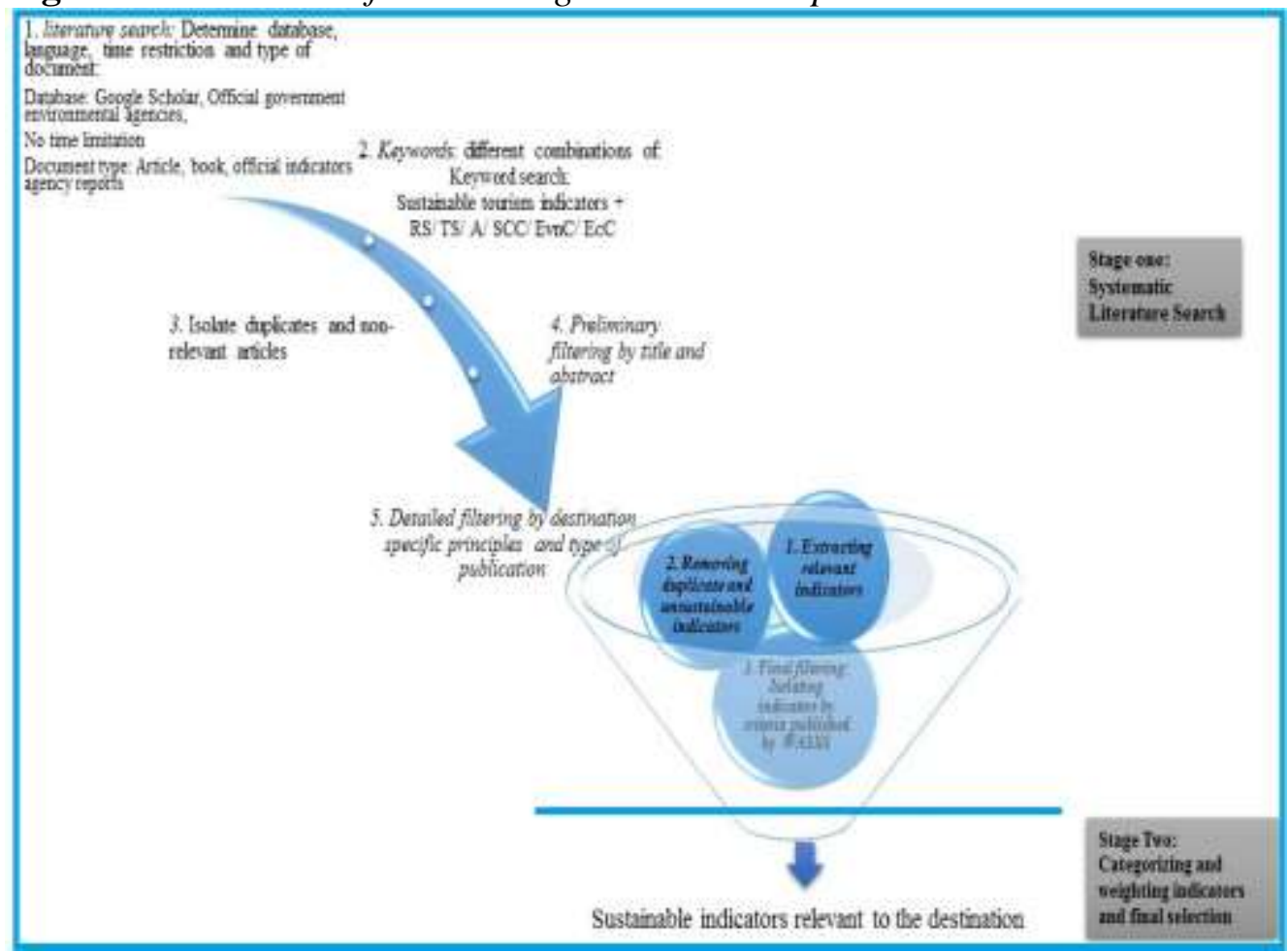

Furthermore, let NI=total number of indicators resulting from stage 1. NI needs then to be used to measure sustainability of the destination across the three dimensions (environment, socio-cultural and economic). Say that Menv, Msc and Meco stand for the final number of indicators to be retained in the assessment of sustainability when selecting indicators resulting from stage 1 across each sustainability dimension, respectively. Such number may be 
determined by a manager or someone interested in a practical, parsimonious model (say for statistical estimation). Subsequently, final indicators relevant to each sustainability dimension are selected in descending order of their IW $_{i}$ until respectively Menv, Msc and Meco have been reached. As such, only the most well-known indicators in the literature as they pertain to the specific situation at hand, hence all the prior filtering in Stage 1 are retained. This completes Stage 2 of the systematic literature review. The comprehensive literature review framework is summarized in Figure 1.

\section{Concluding Remarks}

Main features of sustainability indicators include the ability to characterise monitor and measure sustainability and have therefore been widely adopted in sustainable tourism management and planning. As the set of indicators needs to be uniquely selected for a particular tourist destination, it is essential to rely on conforming sustainability criteria determined by regional or country authorities. Such indicators selection through well-established criteria shapes the assessment process relevant to the destination.

Yet, as sustainable tourism is a multidimensional complex concept, specific to the type of destination, a wider and deeper insight into its assessment through indicators is required. Our research developed a novel framework that calls for a systematic literature search to summarise all existing information on sustainability tourism indicators in a thorough and unbiased manner.

\section{References}

Ahmad M, Jamaluddin M, Alias M, Jalil A (2013) Destination attractiveness of a theme park: a case study in Malaysia. In: A Zainal (Eds.), Hospitality and Tourism: Synergizing Creativity and Innovation in Research p. 153. CRC Press.

Alkemade R, Burkhard B, Crossman N, Nedkov S, Petz K (2014) Quantifying ecosystem services and indicators for science, policy and practice. Ecological Indicators (37): 161-162.

Barney J (1991) Firm resources and sustained competitive advantage. Journal of management 17(1): 99-120.

Blancas F, Lozano-Oyola M, Gonzalez M, Guerrero FM, Caballero R (2011) How to use sustainability indicators for tourism planning: The case of rural tourism in Andalusia (Spain). Science of the Total Environment 412: 28-45.

Blancas F, Caballero J, González R, Lozano-Oyola M, Pérez F (2010a) Goal programming synthetic indicators: an application for sustainable tourism in Andalusian coastal counties. Ecological Economics 69(11): 2158-2172.

Blancas F, González M, Lozano-Oyola M, Pérez F (2010b) The assessment of sustainable tourism: application to Spanish coastal destinations. Ecological Indicators 10(2): 484-492.

Bleischwitz R, Hennicke P (2004) Eco-Efficiency, Regulation, and Sustainable Business: Towards a Governance Structure for Sustainable Development. Cheltenham, UK: Edward Elgar Publishing. 
Board MA (2005) Millennium Ecosystem Assessment. Washington, DC: New Island.

Bossel H (1999) Indicators for Sustainable Development: Theory, Method, Applications. Canada: International Institute for Sustainable Development Winnipeg.

Calgaro E, Lloyd K, Dominey-Howes D (2014) From vulnerability to transformation: a framework for assessing the vulnerability and resilience of tourism destinations. Journal of Sustainable Tourism 22(3): 341-360.

Candela G, Figini P (2012) The Economics of Tourism Destinations. Springer.

Carrera DG, A Mack (2010) Sustainability assessment of energy technologies via social indicators: Results of a survey among European energy experts. Energy Policy 38(2): 1030-1039.

Castellani V, Sala, S (2010) Sustainable performance index for tourism policy development. Tourism Management 31 (6): 871-880.

Cater C, Cater E (2007) Marine Ecotourism: Between the Devil and the Deep Blue Sea. CABI Publishing.

Choi HC, Sirakaya E (2006) Sustainability indicators for managing community tourism. Tourism Management 27(6): 1274-1289.

Commission JRCE (2008) Handbook on Constructing Composite Indicators: Methodology and User Guide. OECD Publishing.

Cottrell SP, Vaske J, Roemer J (2013) Resident satisfaction with sustainable tourism: the case of Frankenwald Nature Park, Germany. Tourism Management Perspectives 8: 42-48.

Cracolici MF Nijkamp P (2009) The attractiveness and competitiveness of tourist destinations: a study of Southern Italian regions. Tourism Management 30(3): 336-344.

Cucculelli M, Goffi G (2015) Does sustainability enhance tourism destination competitiveness? Evidence from Italian Destinations of Excellence. Journal of Cleaner Production 111(Part B): 285-54.

Devuyst D (2001) Introduction to Sustainability Assessment at the Local Level. New York: Columbia University Press.

European Environmental Agency (1999) Environmental Indicators: Typology and Overview. Copenhagen, Denmark: European Environment Agency. Technical report No 25/1999.

Evans L, Cherrett N, Pemsl D (2011) Assessing the impact of fisheries comanagement interventions in developing countries: a meta-analysis. Journal of Environmental Management 92(8): 1938-1949.

Franzoni S (2015) Measuring the sustainability performance of the tourism sector. Tourism Management Perspectives 16: 22-27.

Grant RM (2010) Contemporary Strategy Analysis and Cases: Text and Cases. John Wiley \& Sons.

Hackett SC, Moore MC (2011) Environmental and Natural Resources Economics: Theory, Policy, and the Sustainable Society. New York, USA: ME Sharpe.

Haralambopoulos N, Pizam A (1996) Perceived impacts of tourism: the case of Samos. Annals of Tourism Research 23(3): 503-526.

Heinberg R (2010) What is Sustainability? In: J Kaufmann, D Lerch, B Sheehan, A Perl, W Rees, T Whipple, S Mills, P Whybrow et al. The Post Carbon Reader: Managing the 21st Century's Sustainability Crises. Santa Rosa, USA: Post Carbon Institute: 11-19.

$\mathrm{Hu}$ W, Wall G (2005) Environmental management, environmental image and the competitive tourist attraction.Journal of Sustainable Tourism 13(6): 617-635. 
Jamal T, Jamrozy U (2006) Collaborative networks and partnerships for integrated destination management. In D Buhalis and C Costa (eds) Tourism Management Dynamics-Trends, Management and Tools. Oxford, UK. Elsevier ButterworthHeinemann: 164-172.

James D (2001) Local sustainable tourism indicators. In JJ Lennon. Tourism Statistics: International Perspectives and Current Issues: 188-198. London, UK: Continuum.

Jurado N, Tejada T, García A, González C, Macías C, Peña D, Gutiérrez F, Fernández $\mathrm{G}$ et al. (2012) Carrying capacity assessment for tourist destinations. Methodology for thecreation of synthetic indicators applied in a coastal area. Tourism Management 33: 1337-1346.

Larson S, Herr A (2008) Sustainable tourism development in remote regions? Questions arising from research in the North Kimberley, Australia. Regional Environmental Change 8(1): 1-13.

La Viña R, Hoff G, DeRose AM (2003) The outcomes of Johannesburg: Assessing the world summit on sustainable development. SAIS Review 23(1): 53-70.

Lee KF (2001) Sustainable tourism destinations: the importance of cleaner production. Journal of Cleaner Production 9(4): 313-323.

Lozano-Oyola M, Blancas F, González M, Caballero R (2012) Sustainable tourism indicators as planning tools in cultural destinations. Ecological Indicators 18: 659-675.

Manning T (1996) What tourism managers need to know: A practical guide to the development and use of indicators of sustainable tourism. World Tourism Organization Publications.

Manning T (1999) Indicators of tourism sustainability. Tourism Management 20: 179-182.

Marien M (1992) Environmental problems and sustainable futures: major literature from WCED to UNCED. Futures 24(8): 731-757.

McCool SF, Moisey N, Nickerson N (2001) What should tourism sustain? The disconnect with industry perceptions of useful indicators. Journal of Travel Research 40(2): 124-131.

McElroy JL, De Albuquerque K (1998) Tourism penetration index in small Caribbean islands. Annals of Tourism Research 25(1): 145-168.

Meyer JW, Rowan B (1977) Institutionalized organizations: Formal structure as myth and ceremony. American Journal of Sociology 83(2): 340-363.

Mikulić JJ, Kožić I, Krešić D (2015) Weighting indicators of tourism sustainability: A critical note. Ecological Indicators 48: 312-314.

Miller G (2001) The development of indicators for sustainable tourism: results of a Delphi survey of tourism researchers. Tourism Management 22(4): 351-362.

Miller G, Rathouse K, Scarles C, Holmes K, Tribe J (2010) Public understanding of sustainable tourism. Annals of Tourism Research 37(3): 627-645.

Moldan B, Janoušková S, Hák T (2012) How to understand and measure environmental sustainability: Indicators and targets. Ecological Indicators 17: 4-13.

Moore JF (1993) Predators and prey: a new ecology of competition. Harvard Business Review 71(3): 75-83.

Mowforth M, Munt I (2008) Tourism and Sustainability: Development, Globalisation and New Tourism in the Third World. London, UK: Routledge.

Myers D, Budruk M, Andereck K (2011) Stakeholder involvement in destination level sustainable tourism indicator development: The case of a southwestern US mining town. In: M Budruk, R Phillips (Eds) Quality-of-Life Community Indicators for Parks, Recreation and Tourism Management. Springer: 185-199. 
Nardo M, Saisana M, Saltelli A, Tarantola S (2005) Tools for Composite Indicators Building. European Comission, Ispra.

Peltoniemi M (2006) Preliminary theoretical framework for the study of business ecosystems. Emergence: Complexity \& Organization 8(1): 10-19.

Perez V, Guerrero F, González M, Pérez F, Caballero R (2013) Composite indicator for the assessment of sustainability: the case of Cuban nature-based tourism destinations. Ecological Indicators 29: 316-324.

Pope J, Annandale D, Morrison-Saunders A (2004) Conceptualising sustainability assessment. Environmental Impact Assessment Review 24(6): 595-616.

Rametsteiner E, Pülzl H, Alkan-Olsson J, Frederiksen P (2011) Sustainability indicator development-science or political negotiation? Ecological Indicators 11(1): 61-70.

Roberts S, J Tribe (2008) Sustainability indicators for small tourism enterprises - an exploratory perspective. Journal of Sustainable Tourism 16(5): 575-594.

Rosenström U, Mickwitz P (2004) Documentation report 3 of the ECOREG project. Social and Cultural Indicators Supporting the Measurement of Eco-Efficiency in the Kymenlaakso Region.

Saisana M, Tarantola S (2002) State-of-the-Art Report on Current Methodologies and Practices for Composite Indicator Development. Italy: Ispra.

Saltelli A (2007) Composite indicators between analysis and advocacy. Social Indicators Research 81(1): 65-77.

Schianetz K, Kavanagh L (2008) Sustainability indicators for tourism destinations: a complex adaptive systems approach using systemic indicator systems. Journal of Sustainable Tourism 16(6): 601-628.

Schianetz K, Kavanagh L, Lockington D (2007) Concepts and tools for comprehensive sustainability assessments for tourism destinations: a comparative review. Journal of sustainable Tourism 15(4): 369-389.

Sheate W (2001) European Commission Contract No B4-3040/99/136634/MAR/B4 Volume 1 Main Report. Imperial College Consultants ICON. Retrieved from http://goo.gl/2lRcRl. [Accessed 26 July 2003].

Shields DJ, Solar S, Martin W (2002) The role of values and objectives in communicating indicators of sustainability. Ecological Indicators 2(1): 149-160.

Singh RK, Murty H, Gupta S, Dikshit A (2012) An overview of sustainability assessment methodologies. Ecological Indicators 9(2): 189-212.

Spangenberg JH (2005) Economic sustainability of the economy: concepts and indicators. International Journal of Sustainable Development 8(1-2): 47-64.

Tanguay GA, Rajaonson J, Therrien MC (2013) Sustainable tourism indicators: Selection criteria for policy implementation and scientific recognition. Journal of Sustainable Tourism 21(6): 862-879.

Torres-Delgado A, Palomeque FL (2014) Measuring sustainable tourism at the municipal level. Annals of Tourism Research 49: 122-137.

Torres-Delgadom A, Saarinen J (2014) Using indicators to assess sustainable tourism development: a review. Tourism Geographies 16(1): 31-47.

Twining-Ward L, Butler R (2002) Implementing STD on a small island: Development and use of sustainable tourism development indicators in Samoa. Journal of Sustainable Tourism 10(5): 363-387.

Twining-Ward L (2007) Adapting the indicator approach - practical applications in the south pacific. In: R Black, A Crabtree (Eds.), Quality Assurance in Ecotourism (pp. 116-135). Cambridge, MA.

Valentin A, Spangenberg JH (2000) A guide to community sustainability indicators. Environmental Impact Assessment Review 20(3): 381-392. 
WASSS (2003) Hope for the Future: The Western Australian State Sustainability Strategy. Western Australia: Government of Western Australia, Department of the Premier and Cabinet Perth.

White V, McCrum G, Blackstock KL, Scott A (2006) Indicators of sustainability and sustainable tourism: some example sets. Aberdeen: The Macaulay Institute.

Wickens E, Bakir A, Alvarez MD (2015) Sustainable Destination Development: issues and Challenges. Tourism Planning \& Development 12(1): 1-5.

World Commission on Environment and Development (1987) Our Common Future. Oxford, New York: Oxford University Press.

UNWTO - United Nations World Tourism Organization (2004) Indicators of Sustainable Development for Tourism Destinations: a Guidebook. 